\title{
Coronary Blood Flow Velocity During Percutaneous Transluminal Coronary Angioplasty as a Guide for Assessment of the Functional Result
}

\author{
PATRICK W. SERRUYS, MD, YVES JUILLIĖRE, MD, FELIX ZIJLSTRA, MD, \\ KEVIN J. BEATT, MRCP, PIM J. DE FEYTER, MD, HARRY SURYAPRANATA, MD, \\ MARCEL VAN DEN BRAND, MD, and JOS ROELANDT, MD
}

To Investigate the clinical usefulness of intracoronary Doppler recordings during percutaneous transluminal coronary angloplasty (PTCA), the changes of Intracoronary blood flow velocity during PTCA were assessed in 20 patients with single proximal coronary stenosis, using a Doppler probe endmounted on the tip of a PTCA catheter. A mean of 4 inflations was performed in each patient. Intracoronary velocities were measured before and after each inflation and during peak reactive hyperemia after each transluminal occlusion. Quantitative analysis of the coronary stenosis was assessed before and after PTCA, and the dilatation resulted in an increase in minimal luminal cross-sectional area from $1.1 \pm 0.8$ to $2.7 \pm 1.2 \mathrm{~mm}^{2}$. A gradual and significant improvement $\mathrm{h}$ velocitles was observed after the first 3 dilatations, but in 15 of the 20 patients the resting and hyperemic velocities were not affected by the fourth dilatation. Coronary flow reserve measured during reactive hyperemia after the last dilatation with the PTCA catheter across the lesion was 1.9. This value of coronary flow reserve is compatible with the residual stenosis measured after PTCA when corrected for the presence of the Doppler balloon catheter $\left(0.68 \mathrm{~mm}^{2}\right)$. This application of the Doppler technique may provide a new method of on-line functional monlioring of the PTCA procedure in individual patients, but does not yet allow an accurate prediction of the change in coronary geometry brought about by PTCA.

(Am J Cardiol 1988;61:253-259)

$T_{1}$

he immediate results of percutaneous transluminal coronary angioplasty (PTCA) are usually assessed by coronary angiography but the change in luminal diameter of an artery after the mechanical disruption of its internal wall cannot always be assessed accurately from the detected angiographic contours.1,2 Although the measured residual pressure gradient may have long-term prognostic value, it reflects only the resting coronary hemodynamics. ${ }^{3,4}$ Intracoronary blood flow

From the Thoraxcenter, Erasmus University, Rotterdam, The Netherlands. Dr. Juillière is a recipient of a Research Fellowship from the University Hospital, Nancy, France. Dr. Beatt is a recipient of a Research Fellowship from the British and Netherlands Heart Foundations. Manuscript received June 15, 1987; revised manuscript received October 8,1987 , and accepted October 10.

Address for reprints: P.W. Serruys, MD, Catheterization Laboratory and Laboratory for Clinical and Experimental Image Processing, Thoraxcenter, Erasmus University, P.O. Box 1738, 3000 DR Rotterdam, The Netherlands. velocity measurements with a Doppler probe have been used to investigate regional coronary flow reserve by measuring the maximal reactive hyperemia induced by pharmacologic vasodilation or by ischemia. ${ }^{5-9}$ During PTCA, maximal reactive hyperemia after each transluminal occlusion may be useful in assessing regional changes in coronary flow reserve resulting from the procedure. This study measures the changes in intracoronary blood flow velocity during PTCA with a Doppler probe end-mounted on the tip of a balloon catheter and describes a potentially useful technologic modality that may provide additional information during PTCA.

\section{Methods}

Patients: Twenty patients undergoing elective PTCA for angina pectoris were studied (New York Heart Association functional class II to IV]. Informed consent was obtained for the additional investigations. All patients were studied without premedication, but their medical treatment (nitrates, calcium antagonists 
and $\beta$ blockers) was continued on the day of the procedure. Patients with left ventricular hypertrophy, valvular heart disease, angiographic evidence of collateral circulation, anemia, polycythemia or hypertension were excluded as these conditions may influence coronary flow reserve. ${ }^{10-12}$

Intracoronary blood flow velocity measurements: A 20-MHz ultrasonic crystal mounted on the tip of the angioplasty catheter was used in all patients. The Doppler crystal has a $1.0-\mathrm{mm}$ diameter annulus with a $0.5-\mathrm{mm}$ central hole. Two leads are soldered to the crystal and pass through the catheter between the original $0.5-\mathrm{mm}$ lumen and a thin-walled tube, which serves as a new 0.4-mm lumen for the guidewire (Figure 1). The leads exit near the proximal luer hub and are wired to a 2 pin plug for connection to the pulsed Doppler instrument. Blood flow velocity is measured from the catheter tip transducer using a range-gated 20 $\mathrm{MHz}$ pulsed Doppler instrument. The master oscillator frequency of $20 \mathrm{MHz}$ is pulsed at a frequency of $62.5 \mathrm{kHz}$. Each pulse is approximately $1 \mathrm{~ms}$ in width and therefore contains 20 cycles of the master oscillator frequency. The frequencies chosen allow velocities of up to $100 \mathrm{~cm} / \mathrm{s}$ to be recorded at distances of up to 1 $\mathrm{cm}$ from the catheter tip. The sampling window is individually adjusted to obtain the optimal signal, which usually results in a sampling window of $1.8 \mathrm{~mm}$ (range 1.5 to 2.2). The output of the pulsed Doppler is displayed as a frequency shift $(\Delta \mathrm{f}, \mathrm{kHz}$ ), which can be related to blood flow velocity by the Doppler equation: $\Delta \mathrm{f}=2 \mathrm{~F}(\mathrm{~V} / \mathrm{c}) \cos \mathrm{a}$, where $\mathrm{F}$ is the ultrasonic frequency $(20 \mathrm{MHz}), \mathrm{V}$ is the velocity within the sample volume, $c$ is the speed of sound in blood $(1,500 \mathrm{~m} / \mathrm{s})$ and a is the angle between the velocity vector and the sound beam. Using an end-mounted crystal with the catheter parallel $\left( \pm 20^{\circ}\right)$ to the vessel axis (cos a equals $1 \pm 6 \%$ ), the relation between the Doppler shift and velocity is approximately $3.75 \mathrm{~cm} / \mathrm{s}$ per kHz.${ }^{9}$ Recently, Sibley et $\mathrm{al}^{9}$ validated clinically and experimentally the ability of a similar catheter with an end-mounted piezo-electric crystal to provide accurate continuous on-line measurement of coronary blood flow velocity and vasodilator reserve.
In our laboratory, we verified the accuracy of each velocity probe by correlating velocity recorded with the Doppler probe in a $9 \mathrm{Fr}$ femoral sheath with the volume flow measured by a timed collection of blood from the side branch of the same sheath. Graduated flow rates (range 12 to $165 \mathrm{ml} / \mathrm{min}$ ) and the corresponding velocities (range 1.2 to $8.2 \mathrm{kHz}$ ) were obtained by incremental balloon inflation with the balloon positioned in the sheath. This simple model allows the assessment of the flow-velocity relation at different levels. As previously demonstrated, this relation is linear with correlation coefficients generally $\geq 0.95,5,6,13$ but underestimates true volume flow for flows over $150 \mathrm{ml} / \mathrm{min} .{ }^{9}$ Flow rates of this magnitude, or velocities exceeding $7.5 \mathrm{kHz}$, were never encountered in this study population.

Protocol: After recording the baseline intracoronary blood velocity in the proximal segment, the balloon catheter (Schneider-Shiley dilatation catheter, Shiley Inc.) with a Doppler probe at the tip was advanced across the stenosis and 3 to 7 inflations with pressures up to 12 atmospheres were used to dilate the stenosis. Resting velocities before and after each balloon inflation and those during reactive hyperemia immediately after deflation were recorded with the Doppler probe situated across the stenotic lesion and expressed in $\mathrm{kHz}$. A satisfactory functional result was considered to have been achieved if there was no further increase in peak velocity during reactive hyperemia.

No additional dilatations were then performed and coronary angiography was repeated after removing the PTCA catheter. The balloon diameter size used in this study varied from 2.5 to $3.4 \mathrm{~mm}$. The cross-sectional area of the catheter with the balloon deflated was $0.68 \mathrm{~mm}^{2}$.

Quantitative analysis of the coronary artery: Coronary angiograms were performed in at least 2 orthogonal projections before PTCA and the same projections were repeated after the procedure (Figure 2). The determination of coronary arterial dimensions from 35-mm cinefilm was performed with the computer-based Cardiovascular Angiographic Analysis Sys-

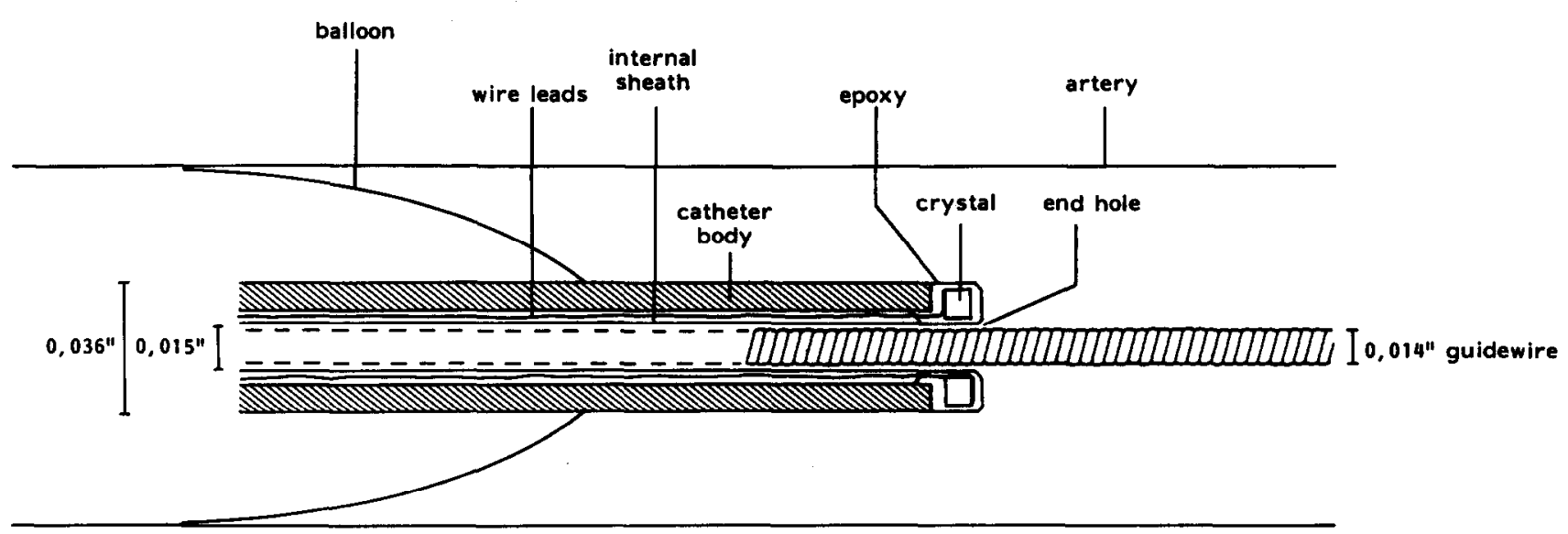

FIGURE 1. Schematlc cross-sectional drawing of Doppler tip angloplasty catheter with Inflated balloon in an artery. 
TABLE I Results of Quantltatlve Coronary Angiography

\begin{tabular}{|c|c|c|c|c|c|c|c|c|c|c|c|c|c|}
\hline \multirow[b]{2}{*}{$P t$} & \multirow[b]{2}{*}{$\begin{array}{l}\text { PTCA } \\
\text { Artery }\end{array}$} & \multirow[b]{2}{*}{$\begin{array}{c}\text { Balloon } \\
\text { Size }\end{array}$} & \multirow[b]{2}{*}{$\begin{array}{l}\text { Balloon } \\
\text { Inflation }\end{array}$} & \multicolumn{3}{|c|}{ Before PTCA } & \multicolumn{5}{|c|}{ After PTCA } & \multirow{2}{*}{ 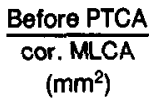 } & \multirow{2}{*}{ 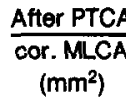 } \\
\hline & & & & $\begin{array}{l}\overline{M L C A} \\
\left(\mathrm{~mm}^{2}\right)\end{array}$ & $\begin{array}{l}\text { DS } \\
(\%)\end{array}$ & $\begin{array}{c}\text { AS } \\
(\%)\end{array}$ & $\begin{array}{l}\overline{M L C A} \\
\left(\mathrm{~mm}^{2}\right)\end{array}$ & $\begin{array}{l}\text { DS } \\
(\%)\end{array}$ & $\begin{array}{c}\text { AS } \\
(\%)\end{array}$ & $\begin{array}{c}\mathrm{RA} \\
\left(\mathrm{mm}^{2}\right)\end{array}$ & $\begin{array}{c}\mathrm{RD} \\
(\mathrm{mm})\end{array}$ & & \\
\hline 1 & LAD & 2.5 & 4 & 0.7 & 61 & 85 & 1.3 & 52 & 76 & 5.3 & 2.59 & 0.0 & 0.6 \\
\hline 2 & LC & 2.5 & 5 & 0.9 & 56 & 80 & 1.4 & 48 & 73 & 5.4 & 2.61 & 0.2 & 0.7 \\
\hline 3 & LAD & 2.5 & 4 & 0.4 & 66 & 88 & 1.4 & 43 & 67 & 4.6 & 2.30 & 0.0 & 0.7 \\
\hline 4 & LAD & 2.5 & 5 & 1.3 & 53 & 77 & 1.2 & 49 & 73 & 5.4 & 2.61 & 0.6 & 0.5 \\
\hline 5 & LAD & 3.0 & 5 & 0.7 & 66 & 88 & 1.2 & 48 & 73 & 4.7 & 2.64 & 0.0 & 0.5 \\
\hline 6 & LAD & 3.0 & 4 & 0.7 & 55 & 77 & 2.0 & 32 & 54 & 4.3 & 2.16 & 0.0 & 1.3 \\
\hline 7 & LC & 3.0 & 6 & 0.5 & 74 & 93 & 2.5 & 28 & 49 & 5.9 & 2.54 & 0.0 & 1.8 \\
\hline 8 & LAD & 3.0 & 4 & 0.7 & 65 & 88 & 3.7 & 13 & 24 & 4.8 & 2.54 & 0.0 & 3.0 \\
\hline 9 & LAD & 3.0 & 5 & 2.9 & 36 & 59 & 5.3 & 23 & 41 & 8.2 & 3.11 & 2.2 & 4.6 \\
\hline 10 & LAD & 3.0 & 4 & 1.9 & 53 & 78 & 3.3 & 39 & 63 & 9.3 & 3.33 & 1.2 & 2.6 \\
\hline 11 & Right & 3.0 & 6 & 0.6 & 71 & 91 & 2.9 & 40 & 64 & 8.1 & 3.02 & 0.0 & 2.2 \\
\hline 12 & LAD & 3.0 & 4 & 0.3 & 78 & 95 & 2.5 & 35 & 55 & 6.1 & 2.79 & 0.0 & 1.8 \\
\hline 13 & LAD & 3.0 & 3 & 0.6 & 67 & 89 & 1.2 & 44 & 67 & 4.8 & 2.47 & 0.0 & 0.5 \\
\hline 14 & LAD & 3.4 & 3 & 2.3 & 54 & 79 & 4.8 & 30 & 51 & 10.3 & 3.65 & 1.6 & 4.1 \\
\hline 15 & LAD & 3.4 & 4 & 1.3 & 52 & 76 & 1.8 & 47 & 72 & 6.2 & 2.75 & 0.6 & 1.1 \\
\hline 16 & LAD & 3.4 & 7 & 0.7 & 72 & 92 & 2.9 & 43 & 67 & 9.0 & 3.37 & 0.0 & 2.2 \\
\hline 17 & LC & 3.4 & 4 & 3.3 & 48 & 72 & 4.1 & 34 & 56 & 9.7 & 3.57 & 2.6 & 3.4 \\
\hline 18 & LAD & 3.4 & 4 & 1.6 & 47 & 72 & 3.5 & 30 & 51 & 7.4 & 2.96 & 0.9 & 2.8 \\
\hline 19 & LAD & 3.4 & 4 & 0.3 & 74 & 93 & 3.0 & 18 & 32 & 4.9 & 2.51 & 0.0 & 2.3 \\
\hline 20 & LAD & 3.4 & 4 & 0.9 & 63 & 86 & 3.5 & 22 & 40 & 6.4 & 2.81 & 0.2 & 2.8 \\
\hline Mean & & & & 1.1 & 60 & 83 & 2.7 & 36 & 57 & 6.5 & 2.82 & 0.5 & 2.0 \\
\hline $\pm S D$ & & & & \pm 0.8 & \pm 11 & \pm 9 & \pm 1.2 & \pm 11 & \pm 15 & \pm 1.9 & \pm 0.41 & \pm 0.8 & \pm 1.2 \\
\hline
\end{tabular}

$A S=$ percentage area stenosis; cor. MLCA = MLCA reduction due to the catheter across the lesion; DS = percentage diameter stenosis; LAD = left anterior descending coronary artery; $L C=$ left circumflex coronary artery; MLCA = minimal luminal cross-sectional area; PTCA $=$ percutaneous transluminal coronary angioplasty; RA = reference interpolated area; $\mathrm{RD}=$ reference interpolated diameter; $\mathrm{SD}=$ standard deviation.

tem. ${ }^{14-16}$ In essence, boundaries of the relevant coronary artery segment are detected automatically from optically magnified and video digitized regions of interest of a selected single cineframe angiogram. The absolute diameter of the stenosis (in $\mathrm{mm}$ ) is determined using the guiding catheter as a scaling device. ${ }^{17}$ The detected contours of the arterial and catheter segments are corrected for pincushion distortion. ${ }^{14} \mathrm{~A}$ computer-estimation of the original arterial dimension at the site of the obstruction is used to define the interpolated reference area or diameter. ${ }^{14,15}$ The interpolated percentage area stenosis and the minimal luminal cross-sectional area $\left(\mathrm{mm}^{2}\right)$ are then calculated and averaged from at least 2, preferably orthogonal, projections.

Statistical methods: The statistical significance of the sequential changes in flow velocity (resting and hyperemic) observed during the procedure was as-
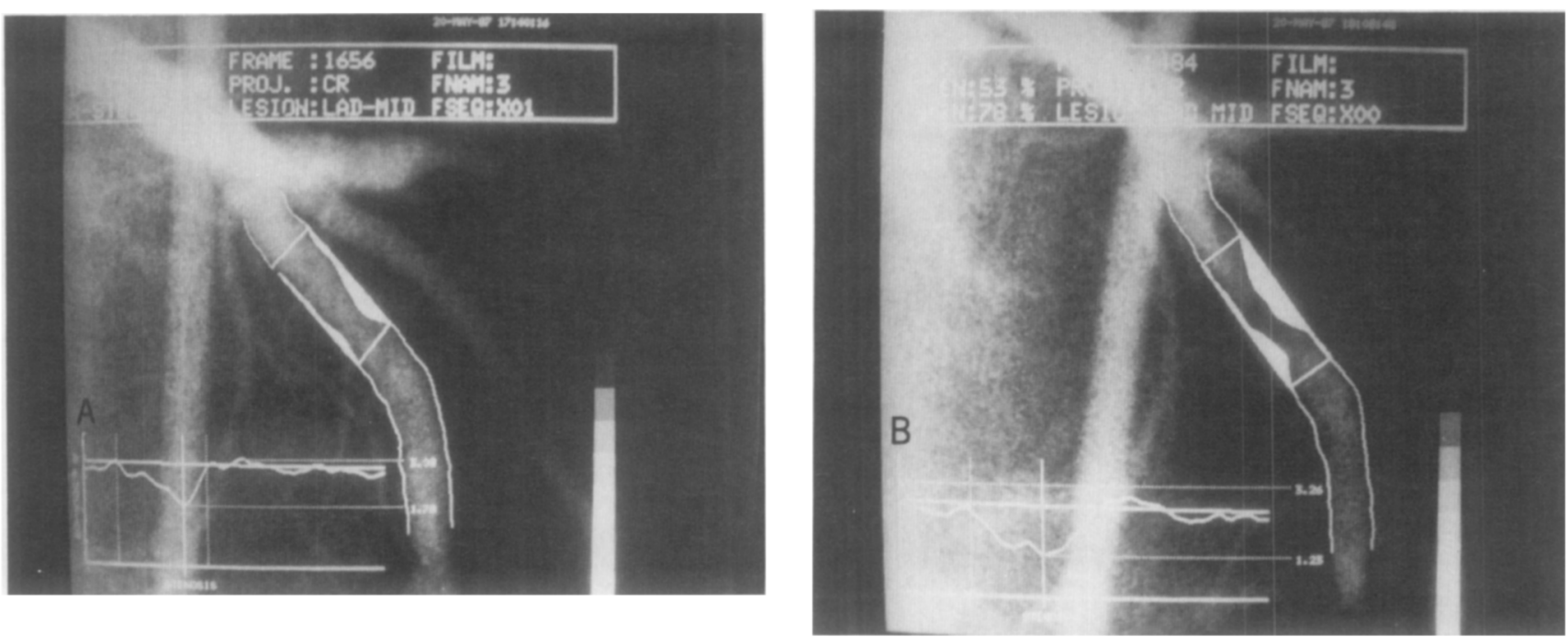

FIGURE 2. Anglograms of a left anterlor descending coronary artery (cranial projection) before, A, and after, B, angloplasty with superimposition of the automated contours at the coronary artery segment of Interest. Beneath thls is shown the dlameter function of the detected contours of the coronary artery. The minimal lumen dlameter (vertical line) and the Interpolated dlameter function (horlzontal Ine) from which the reference diameter is derived are shown. 
scssed by variance analysis and Student $t$ test for paired observations.

\section{Results}

Clinical data: The mean age of the 20 patients (14 men and 6 women) was 54 years (range 41 to 66). Eighteen patients had 1-vessel coronary narrowing and 2 patients 2-vessel narrowing. The investigated and dilate coronary artery was the left anterior descending artery in 16, the left circumflex artery in 3 and the right coronary artery in 1 patient. All patients had normal systolic and diastolic wall motion and an ejection fraction of $>55 \%$. The mean number of balloon inflations were 4.4/patient (range 3 to 7). The PTCA was successful (diameter stenosis $<50 \%$ ) in all patients. Four patients had small localized superficial tear of the dilated coronary artery segment after the procedure.

Quantitative analysis of the coronary angiogram: The minimal lumen cross-sectional area increased from $1.1 \pm 0.8$ to $2.7 \pm 1.2 \mathrm{~mm}^{2}$ (mean \pm standard deviation) (Table I). Percent of area stenosis decreased from $83 \pm 9 \%$ to $57 \pm 15 \%$. Percent of diameter stenosis decreased from $60 \pm 11 \%$ to $36 \pm 11 \%$. The actual

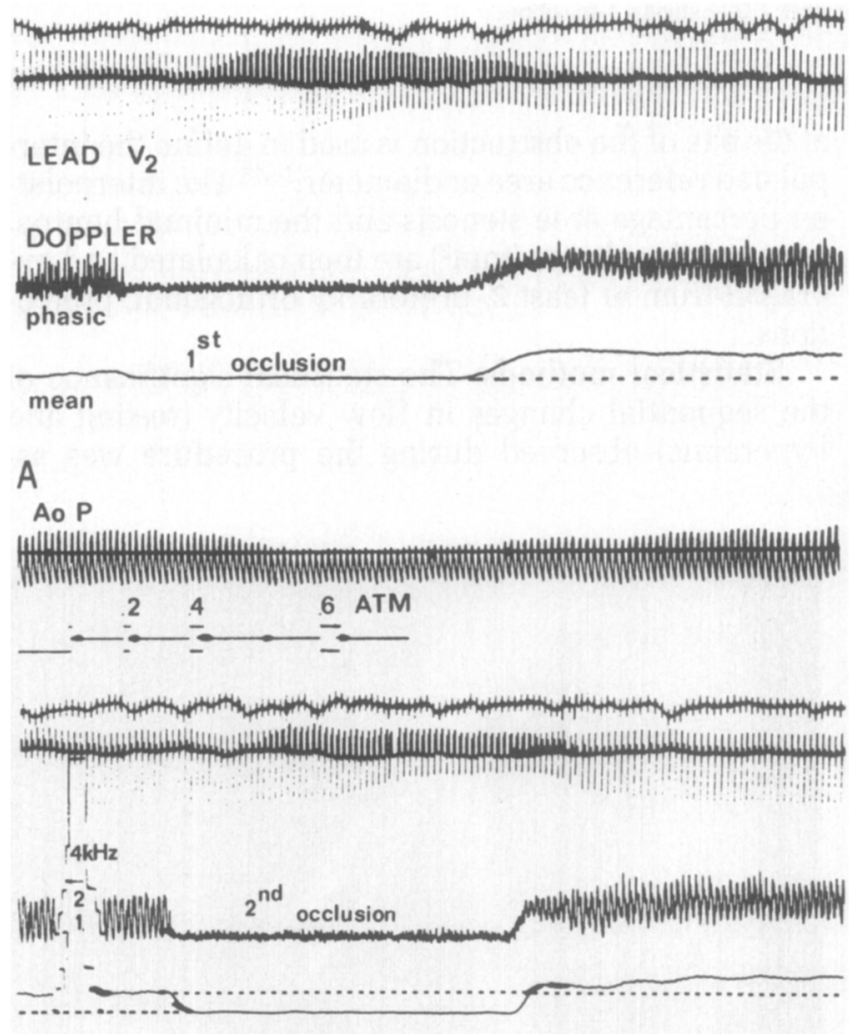

B

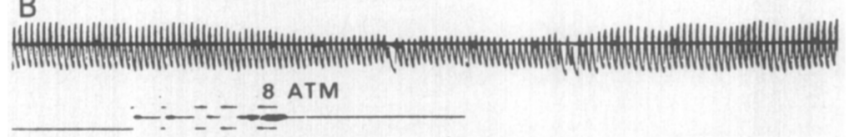

minimal lumen cross-sectional area before and after dilatation with the catheter across the lesion was estimated after subtraction of the area $\left(0.68 \mathrm{~mm}^{2}\right)$ of the PTCA catheter.

Intracoronary Doppler shift during percutaneous transluminal coronary angioplasty: On average, $4 \mathrm{di}-$ latations were performed per patient with sequential mean inflation times of $54,60,63$ and 68 seconds. The inflation pressure increased on average for the 4 inflations from 7.6 to 10.4, 11.4 and 12.0 atmospheres (Figure 3). Reactive hyperemia was maximal after 27 seconds (range 21 to 33) after deflation. The time to subsidence of hyperemia was 56 seconds (range 42 to 74).

After each of the first 3 dilatations, both resting and hyperemic velocities increased (Table II). On average the velocities of the last 2 dilatations did not differ statistically, suggesting that the end result was already achieved by the third dilatation (Figure 4). However, 5 patients $(1,12,16,17$ and 20$)$ still had a substantial increase after the fourth dilatation and might have well benefited from additional dilatations. The ratio of peak hyperemic velocity to resting velocity for each inflation is reported in Table III. When calculating
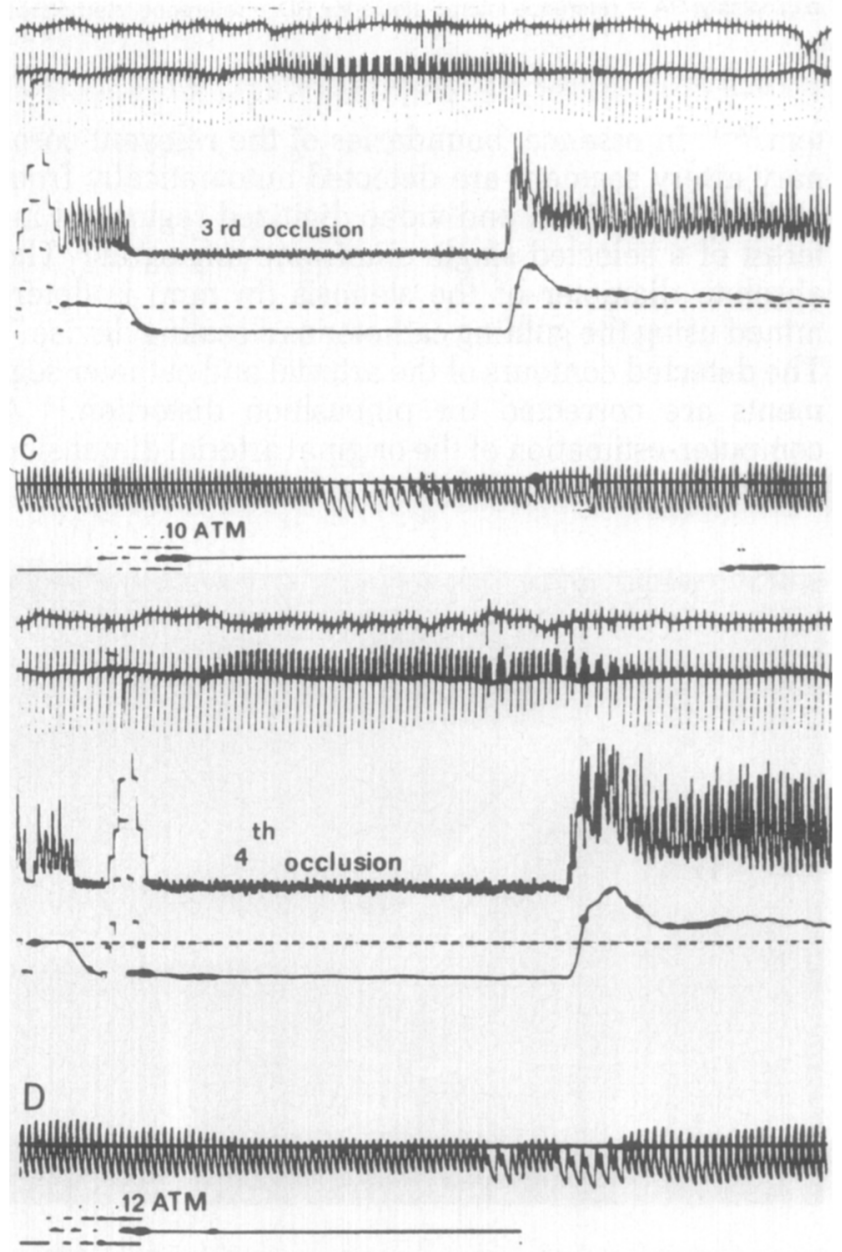

FIGURE 3. Examples of mean and phasic Doppler signals before, during and after balloon inflation. Reactlve hyperemla occurs after balioon deflation. The precordlal lead $V$ shows ST-segment elevation. A, first transiuminal occlusion using a balloon Inflation pressure of 6 atmospheres (Atm). B, second transluminal occlusion using a balioon infiation pressure of 8 Atm. $C$, third transiuminal occlusion using a balloon Inflation pressure of 10 Atm. $D$, fourth transiuminal occlusion using a balloon inflation pressure of 12 Aim. 
TABLE II Doppler Shift (KHz) During Four Sequential Dilatations

\begin{tabular}{|c|c|c|c|c|c|c|c|c|c|c|c|c|}
\hline \multirow[b]{2}{*}{ Pt } & \multicolumn{4}{|c|}{$\mathrm{Vb}$} & \multicolumn{4}{|c|}{ Vh } & \multicolumn{4}{|c|}{$\mathrm{Va}$} \\
\hline & D1 & $\overline{\mathrm{D} 2}$ & $\overline{\mathrm{D} 3}$ & D4 & D1 & D2 & D3 & $\overline{\mathrm{D} 4}$ & D1 & $\mathrm{D} 2$ & D3 & D4 \\
\hline 1 & 1.65 & 1.54 & 2.00 & 3.00 & 1.54 & 2.00 & 1.00 & 2.00 & 1.54 & 2.00 & 1.00 & 2.00 \\
\hline 2 & 0.10 & 0.60 & 0.40 & 0.70 & 0.40 & 0.90 & 1.50 & 0.70 & 0.30 & 0.50 & 0.60 & 0.50 \\
\hline 3 & 0.18 & 0.12 & 0.87 & - & 0.81 & 1.25 & 1.19 & - & 0.18 & 0.87 & 0.56 & - \\
\hline 4 & 0.50 & 0.62 & 0.62 & 0.75 & 1.43 & 1.25 & 1.68 & 1.43 & 0.62 & 0.56 & 0.62 & 1.06 \\
\hline 5 & 0.12 & 0.44 & 1.06 & 1.12 & 0.69 & 1.31 & 1.44 & 1.12 & 0.50 & 1.00 & 1.25 & 0.81 \\
\hline 6 & 0.56 & 3.75 & 2.00 & 2.19 & 4.62 & 3.19 & 3.37 & 2.31 & 0.75 & 2.00 & 2.00 & 1.56 \\
\hline 7 & 0 & 0.25 & 0.25 & 0.31 & 0.56 & 0.31 & 0.81 & 0.56 & 0 & 0 & 0.25 & 0.25 \\
\hline 8 & 0.12 & 0.12 & 1.12 & 0.81 & 0.25 & 0.56 & 1.37 & 1.87 & 0.12 & 0.12 & 0.50 & - \\
\hline 9 & 0.62 & 0 & 0.56 & 0.50 & 0.62 & 0.81 & 1.06 & 2.43 & 0.62 & 0 & 0.75 & 1.25 \\
\hline 10 & 0.12 & 0.87 & 1.18 & 1.25 & 1.06 & 1.62 & 2.81 & 3.25 & 0.81 & 1.25 & 1.18 & 0.56 \\
\hline 11 & 0.12 & 0.37 & 0.62 & 0.75 & 0.56 & 0.75 & 1.06 & 0.93 & 0.56 & 0.56 & 0.43 & 0.37 \\
\hline 12 & 0 & 0.12 & 0.37 & 0.50 & 0.25 & 0.94 & 0.88 & 0.48 & 0 & 0.62 & 0.37 & 0.50 \\
\hline 13 & 0 & 1.00 & 1.80 & - & 0.27 & 3.15 & 2.61 & . & 0.09 & 2.34 & 2.43 & - \\
\hline 14 & 1.06 & 1.25 & 2.75 & - & 2.18 & 1.68 & 5.50 & - & 1.25 & 1.12 & 2.87 & - \\
\hline 15 & 0.90 & 0.95 & 0.65 & 0.95 & 1.30 & 1.05 & 1.50 & 1.35 & 1.20 & 1.05 & 1.00 & 1.25 \\
\hline 16 & 0.50 & 1.81 & 1.62 & 1.50 & 2.06 & 2.12 & 1.93 & 3.18 & 1.81 & 1.68 & 0.75 & 1.75 \\
\hline 17 & 0.10 & 0.10 & 0.15 & 0.65 & 0.35 & 0.60 & 0.35 & 1.10 & 0.15 & 0.50 & 0.30 & 0.70 \\
\hline 18 & 0 & 0 & 0.75 & 1.06 & 0.50 & 1.00 & 1.18 & 2.25 & 0 & 0.25 & 0.50 & 1.25 \\
\hline 19 & 0.37 & 1.18 & 1.43 & 1.18 & 3.00 & 1.81 & 2.12 & 2.43 & 0.87 & 1.37 & 1.25 & 1.08 \\
\hline 20 & 0.37 & 0.56 & 0.50 & 0.81 & 0.56 & 0.75 & 1.06 & 2.00 & 0.43 & 0.75 & 0.50 & 0.93 \\
\hline Mean & 0.37 & 0.78 & 1.03 & 1.06 & 1.15 & 1.35 & 1.72 & 1.73 & 0.59 & 0.93 & 0.95 & 0.99 \\
\hline \multirow[t]{2}{*}{$\pm \mathrm{SE}$} & \pm 0.10 & \pm 0.19 & \pm 0.16 & \pm 0.16 & \pm 0.25 & \pm 0.18 & \pm 0.26 & \pm 0.21 & \pm 0.12 & \pm 0.15 & \pm 0.16 & \pm 0.13 \\
\hline & & $\uparrow$ & & & & ${ }^{*}$ & & & & 7 & & IS \\
\hline
\end{tabular}

Data are individual and mean \pm standard error (SE).

$\mathrm{D}=$ dilatation; $\mathrm{Va}=$ resting velocity after dilatation; $\mathrm{NS}=$ difference not significant; $\mathrm{Vb}=$ resting velocity before dilatation; Vh = peak reactive hyperemia. Variance analysis plus paired $t$ test: ${ }^{*} p<0.05 ;{ }^{\dagger} p<0.001$.

"coronary flow reserve" using the peak hyperemic velocity and the resting velocity recorded before the first 2 dilatations, we observed a paradoxical decrease of the ratio from $3.9 \pm 0.6$ to $1.9 \pm 0.2$. This is due to the major increase in resting velocity whose values were very low before the first inflation, with the catheter across the undilated lesion. When this ratio is based on the resting velocity recorded after dilatation, the coronary flow reserve differed little from 1 inflation to the next; values ranged between 1.7 and 2.1. This absence of change was confirmed statistically by variance analysis. In other words, this ratio does not seem to be a useful functional guidelines for PTCA, whereas the peak hyperemic velocity after successive balloon deflations shows a gradual and significant increase, leveling off in most patients after the third dilatation.

\section{Discussion}

We measured the changes in the intracoronary blood flow velocity during PTCA by means of a Doppler tip balloon catheter. Our original purpose was to use this information as an on-line assessment of the functional result of the dilatation, with the PTCA catheter still across the stenosis. The technical innovation of this catheter is the combination of a diagnostic and therapeutic tool. Although the catheter is a prototype of first generation, it provides a unique opportunity to assess the reactive hyperemia in awake human beings.

The poststenotic velocities recorded with the catheter across the lesion are low when compared with the previously published data that document values recorded proximal to the stenotic lesion..$^{9,13,18}$ Recently it has been suggested ${ }^{19}$ that the "zero crossing" method underestimates poststenotic velocity possibly because of disturbance of laminar flow and this may also explain the discrepancy between our results and those previously published. The routine calibration of each Doppler probe by the timed blood volume collection from the femoral sheath (cross-sectional area, $6.9 \mathrm{~mm}^{2}$ ) makes it unlikely that the intracoronary flow velocities recorded in this study with an end-mounted Doppler catheter are in error.

The duration of the hyperemia observed in all patients was longer than that in the previously reported

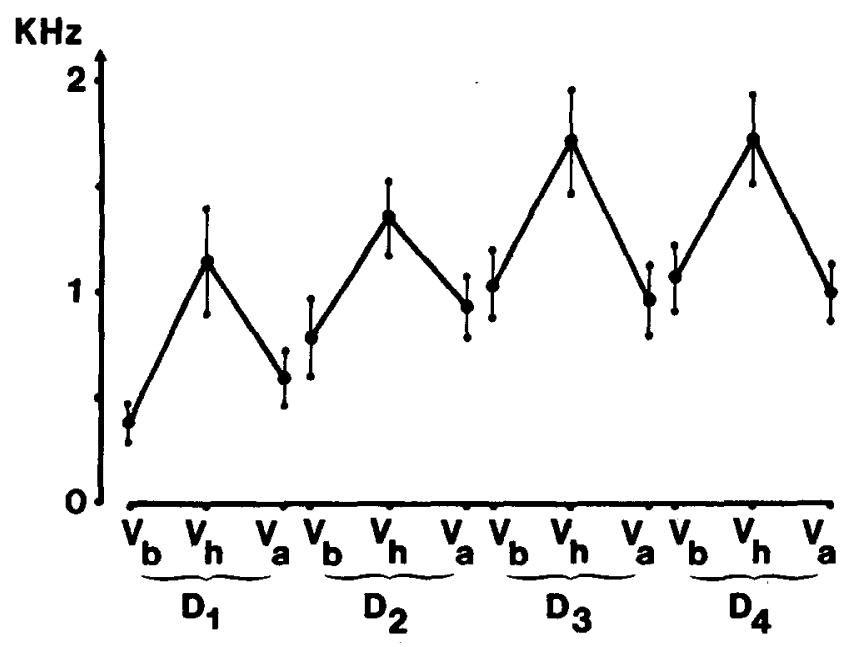

FIGURE 4. Doppler shift (KHz, mean \pm standard error) during 4 sequential dilatations (D). $\mathrm{Va}=$ resting velocity after dilatation; $\mathrm{Vb}$ $=$ resting velocity before dilatation; $\mathrm{Vh}=$ peak reactlve hyperemia. 
TABLE III Ratios of Peak Reactive Hyperemla to Resting Velocity After Each Dilatation

\begin{tabular}{|c|c|c|c|c|c|c|c|c|}
\hline \multirow[b]{2}{*}{ Pt } & \multicolumn{2}{|c|}{ Dilatation 1} & \multicolumn{2}{|c|}{ Dilatation 2} & \multicolumn{2}{|c|}{ Dilatation 3} & \multicolumn{2}{|c|}{ Dilatation 4} \\
\hline & $\mathrm{Vh} / \mathrm{Vb}$ & $\mathrm{Vh} / \mathrm{Va}$ & $\overline{\mathrm{Vh} / \mathrm{Vb}}$ & $\mathrm{Vh} / \mathrm{Va}$ & $\overline{\mathrm{Vh} / \mathrm{Vb}}$ & $V h / V a$ & $\overline{\mathrm{Vh} / \mathrm{Vb}}$ & $\mathrm{Vh} / \mathrm{Va}$ \\
\hline 1 & 0.93 & 1.00 & 1.30 & 1.00 & 0.50 & 1.00 & 0.67 & 1.00 \\
\hline 2 & 4.00 & 1.33 & 1.50 & 1.80 & 3.75 & 2.50 & 1.00 & 1.40 \\
\hline 3 & 4.50 & 4.50 & 10.41 & 1.33 & 1.36 & 2.12 & - & - \\
\hline 4 & 2.86 & 2.31 & 2.02 & 2.23 & 2.71 & 2.71 & 1.91 & 1.35 \\
\hline 5 & 5.75 & 1.38 & 2.97 & 1.31 & 1.36 & 1.16 & 1.00 & 1.38 \\
\hline 6 & 8.25 & 6.16 & 0.85 & 1.59 & 1.68 & 1.68 & 1.05 & 1.48 \\
\hline 7 & - & - & 1.24 & - & 3.24 & 3.24 & 1.80 & 2.24 \\
\hline 8 & 2.08 & 2.08 & 4.66 & 4.66 & 1.22 & 2.74 & 2.30 & - \\
\hline 9 & 1.00 & 1.00 & - & - & 1.89 & 1.41 & 4.86 & 1.94 \\
\hline 10 & 8.83 & 1.30 & 1.86 & 1.29 & 2.38 & 2.38 & 2.76 & 5.80 \\
\hline 11 & 3.70 & 1.00 & 2.02 & 1.33 & 1.71 & 2.46 & 1.24 & 2.51 \\
\hline 12 & - & - & 7.83 & 1.51 & 2.37 & 2.37 & 0.96 & 1.00 \\
\hline 13 & - & 3.00 & 3.15 & 1.35 & 1.45 & 1.07 & - & - \\
\hline 14 & 2.05 & 1.74 & 1.34 & 1.50 & 2.00 & 1.91 & - & - \\
\hline 15 & 1.44 & 1.33 & 1.10 & 1,00 & 2.30 & 1.50 & 1.42 & 1.08 \\
\hline 16 & 4.12 & 1.13 & 1.17 & 1.26 & 1.19 & 2.57 & 2.12 & 1.81 \\
\hline 17 & 3.50 & 2.33 & 6.00 & 1.20 & 2.33 & 1.16 & 1.69 & 1.57 \\
\hline 18 & - & - & - & 4.00 & 1.57 & 2.36 & 2.12 & 1.80 \\
\hline 19 & 8.10 & 3.45 & 1.53 & 1.32 & 1.47 & 1.70 & 2.05 & 2.29 \\
\hline 20 & 1.51 & 1.30 & 1.33 & 1.00 & 2.12 & 2.12 & 2.46 & 2.15 \\
\hline Mean & 3.91 & 2.14 & 2.90 & 1.70 & 1.93 & 2.01 & 1.85 & 1.92 \\
\hline $\pm S E$ & \pm 0.65 & \pm 0.35 & \pm 0.63 & \pm 0.24 & \pm 0.17 & \pm 0.14 & \pm 0.24 & \pm 0.28 \\
\hline
\end{tabular}

Data are individual and mean \pm standard error (SE).

Abbreviations as in Table II.

studies. ${ }^{8,10,20}$ However, in contrast to our results, previous results were obtained after occlusion of normal arteries and after a shorter occlusion time (20 seconds maximal). Marcus et $\mathrm{al}^{20}$ have demonstrated that the duration of the hyperemic response increased progressively with increasing duration of occlusion.

Intracoronary blood flow velocity measurements with a Doppler probe have previously been used to investigate regional coronary flow reserve, assessing the maximal reactive hyperemia induced by pharmacologic vasodilation or ischemia. ${ }^{5-9}$ However, because coronary flow reserve is a ratio between maximal and resting coronary blood flow, any increase in resting flow results in a decrease of this ratio. This phenomenon was observed after the first 2 dilatations when the resting velocity preceding the inflation was used as the denominator of the ratio (peak hyperemic velocity/ resting velocity). If the resting velocity after the deflation was used as denominator, the ratio remained unchanged during 4 dilatations; this alternative is therefore useless as a functional guideline during the procedure. Because peak hyperemic velocity shows a gradual increase with successive dilatations, which presumably reflects progressive enlargement of the lumen stenotic, we attempted to correlate the crosssectional area of the stenotic lesion "corrected" for the presence of the catheter across the stenosis, with the absolute value of the peak velocity during reactive hyperemia. Despite an orderly ranking of the 2 parameters, no close correlation ( $\mathrm{r}=0.41$ ) could be established. Ideally cross-sectional areas measured after each stepwise enlargement of the lumen by the gradual inflation of the balloon should have been correlated with the peak hyperemic velocity after the transluminal occlusion. Unfortunately, the poor quality of the coronary angiography performed with the PTCA catheter in the guiding catheter precludes quantitative analysis.

In the setting of PTCA, the absence of a precise mathematical relation between the peak hyperemic velocity measured after the last inflation and the post-PTCA "corrected" minimal lumen cross-sectional area is not so surprising. First, the changes in luminal size of an artery after the mechanical disruption of its internal wall may be difficult to assess by angiographic means. ${ }^{1,2}$ The irregular shape with internal tears that fill with contrast medium to a variable extent will result in some overestimation of the true functional luminal size immediately after PTCA. Second, the extent of coronary atherosclerosis may be difficult to delineate angiographically. McPherson et $\mathrm{al}^{21}$ have documented that substantial intimal atherosclerosis, resulting in diffuse documented obstructive disease and involving the entire length of an epicardial artery, is often present, even when angiograms reveal only discrete lesions. As a consequence, relative measure. ments of stenosis severity are an inadequate approach to assessing the severity of coronary obstructions. In addition, the calculated cross-sectional area of the stenotic lesion after the subtraction of the cross-sectional area of the catheter (mean $2.0 \pm 1.2 \mathrm{~mm}^{2}$, range 0.5 to 4.6) clearly suggests that the catheter is not only impeding the flow through the stenotic lesion, even after dilatation, but might unpredictably disturb the velocity profile in the poststenotic segment. ${ }^{22}$ Further miniaturization of the catheter may improve this major drawback. For all these reasons, the measurement of the peak velocity with this prototype catheter of first generation does not permit an accurate on-line prediction of the morphologic change of the stenotic lesion. How- 
ever, during sequential dilatations the plateau observed in the peak hyperemic and resting velocity signals still provides valuable information, which indicates that no further improvement in flow velocity can be expected from additional dilatations.

Some investigators ${ }^{23-26}$ have reported that PTCA does not normalize coronary flow reserve. Wilson et $\mathrm{al}^{18}$ have shown in a human study that the impaired coronary flow reserve is directly related to the severity of the stenosis. Cross-sectional area measured immediately after PTCA generally increased approximately 3 -fold as a result of the procedure, but remained grossly abnormal and was generally less than half the diameter of the inflated dilating balloon. ${ }^{27}$ In a previous study, $\mathrm{we}^{16}$ established the relation between cross-sectional area $(0 \mathrm{~A})$ and coronary flow reserve (CFR): CFR $=0.28+0.91[0 \mathrm{~A})-0.039(0 \mathrm{~A})^{2}$. A measured crosssectional area of $2.7 \mathrm{~mm}^{2}$ after PTCA would correspond to an average coronary flow reserve of 2.4 . However, if the catheter is taken into consideration, calculated coronary flow reserve is 1.94 , consistent with the coronary flow reserve of 1.92 measured in this study. Therefore, this persisting reduction in cross-sectional area is by itself a sufficient explanation for the limited restoration of coronary flow reserve, although it does not exclude other contributing pathophysiologic mechanisms.

\section{References}

1. Block PC, Myler RK, Stertzer S, Fallon JT. Morphology after transluminal angioplasty in human beings. N Engl I Med 1981;305:382-385

2. Serruys PW, Reiber JHC, Wijns W, van den Brand M, Kooijman CJ, ten Katen H], Hugen holtz PG. Assessment of percutaneous transluminal coronary angioplasty by quantitative coronary angiography: diameter versus densitometric area measurements. Am J Cardiol 1984;54:482-488.

3. Leimgruber PP, Roubin GS, Hollman J, Cotsonis GA, Meier B, Douglas JS, King SB, Grüntzig AR. Restenosis after successful coronary angioplasty in patients with single-vessel disease. Circulation 1986;73:710-717.

4. Serruys PW, Wijns W, Reiber JHC, de Feyter PJ, van den Brand M, Piscione F, Hugenholtz PG. Values and limitations of transstenotic pressure gradients measured during percutaneous coronary angioplasty. Herz 1985;6:337-342. 5. Cole JS, Hartley CJ. The pulsed Doppler coronary artery catheter. Preliminary report of a new technique for measuring rapid changes in coronary artery flow velocity in man. Circulation 1977;56:18-25.

6. Hartley CJ, Cole JS. An ultrasonic pulsed Doppler system for measuring blood flow in small vessels. I Appl Physiol 1974;37:626-629.

7. Sibley D, Bulle T, Baxley W, Dean L, Chandler I, Whitlow P. Acute changes in blood flow velocity with successful coronary angioplasty (abstr). Circulation 1986;74 (suppl II):193.

8. Sibley D, Bulle T, Baxley W, Dean L, Whitlow P. Continuous on-line assessment of coronary angioplasty with a Doppler tipped balloon dilatation catheter [abstr). Circulation 1986;74 (suppl II):459.
9. Sibley DH, Millar HD, Hartley CJ, Whitlow PL. Subselective measurement of coronary blood flow velocity using a steerable Doppler catheter. JACC 1986;8:1332-1340.

10. Marcus ML. Physiological effects of a coronary stenosis. In: The Coronary Circulation in Health and Disease. New York: McGraw-Hill, 1983:242-269. 11. Marcus ML. Effects of cardiac hypertrophy on the coronary circulation. In: The Coronary Circulation in Health and Disease. New York: McGrawHill, 1983:285-306.

12. Marcus ML, Doty DB, Hiratzka LP, Wright CB, Eastham CL. Decreased coronary reserve: a mechanism for angina pectoris in patients with aortic stenosis and normal coronary arteries. N Engl I Med 1985;307:1362-1366. 13. Wilson RF, Laughlin DE, AckeIl PH, Chilian WM, Holida MD, Hartley CJ, Armstrong $\mathrm{ML}_{\text {; }}$ Marcus ML, White CW. Transluminal subselective measurement of coronory artery blood flow velocity and vasodilator reserve in man. Circulation 1985;72:82-92.

14. Reiber JHC, Kooijman CJ, Slager CJ, Gerbrands JJ, Schuurbiers JHC, den Boer A, Wijns W, Serruys PW, Hugenholtz PG. Coronary artery dimensions from cineangiograms; methodology and validation of a computer-assisted analysis procedure. IEEE Trans Med Imaging 1984;MI-3:131-141.

15. Reiber JHC, Serruys PW, Kooijman CJ, Wijns W, Slager CJ, Gerbrands J], Schuurbiers JCH, den Boer A, Hugenholtz PG. Assessment of short-, medium-, and long-term variations in arterial dimensions from computer-assisted quantification of coronary cineangiograms. Circulation 1985;71:280-288.

16. Zijlstra $F$, van Ommeren I, Reiber [HC, Serruys PW. Does quantitative assessment of coronary artery dimensions predict the physiological significance of a coronary stenosis? Circulation 1987; 75:1154-1161.

17. Reiber JHC, Kaoijman CJ, den Bner A, Serruys PW. Assessment of dimensions and image quality of coronary contrast catheters from cineangiograms. Cath Cardiovasc Diagn 1985;11:521-531.

18. Wilson RF, Marcus ML, White CW. Prediction of the physiologic significance of coronary arterial lesions by quantitative lesion geometry in patients with limited coronary artery disease. Circulation 1987;75:723-732.

19. Kajiya F, Ogasawara Y, Tsujioka K, Nakai M, Goto M, Wada Y, Tadaoka S, Matsuoka S, Mito K, Fuwruara T. Evaluation of human coronary blood flow with an 80 channel $20 \mathrm{MHz}$ pulsed Doppler velocimeter and zero-cross and Fourier tranform methods during cardiac surgery. Circulation 86;74 (suppl III):53-60.

20. Marcus ML, Wright C, Doty D, Eastham C, Laughlin D, Krumm P, Fastenow C, Brody M. Measurements of coronary velocity and reactive hyperemia in the coronary girculation of humans. Circ Res 1981;49:877-891.

21. McPherson DD, Hiratzka LF, Lamberth WC, Brandt B, Hunt M, Kieso RA, Marcus ML, Kerber RF. Delineation of the extent of coronary atherosclerosis by high-frequently epicardial echocardiography. N Engl I Med 1987:316:304309 .

22. Kilpatrick D, Webber SB. Intravascular blood velocity in simulated coronary artery stenoses. Cathet Cardiovasc. Diagn 1986;12:317-323.

23. Johnson MR, Wilson RF, Skarton DI, Collins SM, White CW. Coronary lumen area immediately after angioplasty does not correlate with coronary vasodilator reserve; $a$ video-densitometric study (abstr). Circulation 1986;74 (suppl II):193.

24. O'Neill WW, Walton JA, Bates ER, Colfer HT, Aueron FM, Le Free MT, Pitt B, Vogel RA. Criteria for successful coronary angioplasty as assessed by alterations in coronary vasodilatory reserve. JACC 1984;3:1382-1390.

25. Wilson RF, Aylward PE, Talman CL, White CW. Does percutaneous transluminal coronory angioplasty restore normal coronary vasodilator reserve? [abstr). Circulation 1985;72 (suppl II):397.

26. Zijlstra F, Reiber JHC, Juillière Y, Serruys PW. Normalization of coronary flow reserve by percutaneous transluminal coronary angioplasty. Am I Cordiol 1988;61:55-60.

27. Johnson MR, Brayden GP, Ericksen EE, Collins SM, Skaron DI, Harrison DG, Marcus ML, White CW. Changes in cross-sectional area of the coronary lumen in the six months after angioplasty: a quantitative analysis of the variable response to percutaneous transluminal angioplasty. Circulation 1986; 73:467-475. 